\title{
PERFORMA PEMIMPIN PEREMPUAN DI PARLEMEN
}

Oleh:

\author{
ANIS ENDANG SM, ADINDA TESSA NAUMI \\ Program Studi Ilmu Komunikasi Fakultas Ilmu-Ilmu Sosial \\ Universitas Dehasen Benngkulu
}

\begin{abstract}
This research aims to seekthe performance of women leaders in the Regional House of Representativesof Bengkulu City in communicating politics and representing themselves as leaders in a "masculine" world that is considered cruel to women. This research used a descriptive qualitative method. Data were collected by using in-depth interview and observation to three women leaders.Based on the results, it could be concluded that the female parliamentary leaders conducting political communication feminine style leadership such as engaging and directing parliamentarians they led in carrying out their duties. However, when it's needed, they remain firm, but not arrogant.
\end{abstract}

Keywords: political communication, women leaders, gender, parliament

\section{PENDAHULUAN}

Mill dan Taylor menyebut bahwa jika masyarakat ingin mencapai kesetaraan seksual atau keadilan gender, maka masyarakat harus memberikan perempuan hak politik dan kesempatan, serta pendidikan yang sama yang dinikmati oleh laki-laki (Tong, 2010: 16). Kesempatan bagi perempuan untuk menggunakan hak politik secara legal sudah tersedia, begitupun dengan akses pendidikan. Hal ini terlihat dari munculnya perempuanperempuan yang menjabat di berbagai institusi publik, termasuk parlemen.

Betty Friedan pada 1967 membuat landasan Undang-undang Hak Perempuan sebagai upaya untuk memastikan perempuan mempunyai hak yang sama dengan laki-laki (Tong, 2010: 13). Pergerakan feminis telah mampu membawa perempuan keluar ke ranah publik. Keterlibatan perempuan dalam politik tentu diekspektasikan akan membawa kebijakan yang baik bagi perempuan dan meminimalisir bias gender.
Peran perempuan dalam pengatur atau pengambil kebijakan di masyarakat berkaitan dengan bagaimana pemosisian perempuan atas laki-laki. Masih minimnya perempuan yang menduduki jabatan tertinggi dalam parlemen berkaitan dengan hubungan kekuasaan. Richmond - Abbott (1992 :13) menyebut bahwa hubungan kekuasaan kerap menjadi bagian dari sistem stratifikasi dan biasanya berkaitan dengan pihak yang berkuasa dan pihak yang lemah. Dengan demikian superioritas laki-laki menjadi persoalan ketika perempuan menduduki jabatan yang lebih tinggi.

Kemajuan pergerakan perempuan dalam politik dapat dilihat dari beberapa perempuan yang berhasil meraih jabatan tertinggi dalam parlemen bahkan memimpin negara. Adalah Margaret Thatcher yang karier politiknya telah menjadi salah satu yang paling luar biasa dari zaman modern (http://www.biography.com/people/margar et-thatcher-9504796). Dalam konteks Indonesia, kita pernah memiliki presiden 
perempuan. Walaupun menjadi polemik berkepanjangan, naiknya Megawati sebagai presiden sebenarnya merupakan bukti bahwa Indonesia adalah negara yang mendukung kesetaraan gender. Namun dikatakan Syah (2014: 27-28), gaya kepemimpinan Megawati berbeda dengan Thatcher. Megawati lebih memainkan keterikatan emosi (pathos) sebagai bagian dari rakyat kecil. Megawati juga cenderung lebih menunjukkan 'keperempuanannya' yang bersifat keibuan. Bahkan Megawati yang dikutip dalam Ma'ruf (2013:135) mengatakan "Saat saya kalah dalam pilpres, saya tahu penyebabnya apa. Ternyata para ibu-ibu tidak memilih saya sebagai presiden". Hal ini menunjukkan Megawati berasumsi bahwa status sebagai perempuan seharusnya menjadi sumber kekuatan dalam memimpin.

Saat ini di Indonesia, beberapa daerah telah dipimpin oleh perempuan seperti Tri Rismaharini (Wali Kota Surabaya) dan Illiza Sa'aduddin Djamal (Wali Kota Banda Aceh). Di parlemen pun, keanggotaan parlemen perempuan telah mengalami peningkatan, walaupun angkanya tak cukup signifikan. Beberapa perempuan bahkan mampu menjadi ketua komisi atauketua parlemen. Pada periode 2014-2019, perempuan yang berhasil menduduki kursi pimpinan DPRD diantaranya, Sumini (Wakil ketua I DPRD Inhu), Septina Primawati Rusli (Ketua DPRD Riau), Suparmi (ketua DPRD Kota Tangerang), dan Sri Handayani (wakil ketua DPRD Blora). Dalam konteks Bengkulu, sejak September 2014 DPRD Kota Bengkulu diketuai oleh seorang perempuan. Selain itu, dari tiga posisi ketua komisi, dua diantaranya dipimpin oleh perempuan.

Tulisan ini bertujuan untuk mengetahui performa perempuan yang berhasil menjadi pemimpin di DPRD Kota Bengkulu melalui komunikasi politik dan gaya kepemimpinan yang dilakukan. Komunikasi politik didefinisikan Rush dan Althoff (dalam Zamroni, 2013: p. 9) sebagai suatu proses diteruskannya informasi politik yang relevan dari satu bagian ke bagian lainnya. Komunikasi politik tidak hanya terjadi dalam sistem politik, namun juga diantara sistem-sistem sosial lain dengan sistem politik yang terjadi secara berkesinambungan dan meliputi pertukaran informasi antara individu-individu dengan kelompokkelompok pada semua tingkatan.Windlesham (dalam Suryani, 2010: p. 26) menyebut komunikasi politik sebagai "the deliberate passing of a political message by a sender to a reciever with the intention of making the reciever behave in a way that might not otherwise have done". Sebagai sebuah elemen yang dinamis dan menentukan sosialisasi dan partisipasi politik, komunikasi politik merupakan unsur penting. Disebutkan Zamroni (2013: p.9), komunikasi politik menentukan corak perilaku politik politisi.

Sedangkan kepemimpinan adalah suatu seni memengaruhi perilaku manusia, baik perorangan maupun kelompok. Dalam suatu organisasi, kepemimpinan memegang peranan sangat penting, karena keberhasilan dan kegagalan organisasi ditentukan oleh faktor kepemimpinan (Thoha, 2010: 9).

\section{METODE PENELITIAN}

Penelitian ini merupakan penelitian kualitatif dengan pendekatan deskriptif. Kriyantono (2009: 56-57) mengatakan bahwa metode kualitatif yang bertujuan untuk menjelaskan fenomena sedalamdalamnya ini tidak mengutamakan besaran populasi atau sampling, karena yang dipersoalkan dalam penelitian kualitatif adalah kedalaman (kualitas) data.

Subjek dalam penelitian ini anggota DPRD Kota Bengkulu perempuan yang menduduki jabatan pimpinan, yaitu Ketua DPRD Kota Bengkulu (Erna Sari Dewi, SE), Ketua Komisi II(Baidari Citra Dewi, SH) dan Ketua Komisi III (Mardensi, S.Ag). Penentuan informan dalam penelitian ini dilakukan secara (purposive). Adapun tujuan dari penggunaan teknik ini adalah untuk mendapatkan data yang valid 
dan secara jelas dapat menjawab dari rumusan masalah penelitian yang diangkat.

Teknik pengumpulan data yang digunakan dalam penelitian ini adalah wawancara mendalam observasi, dan dokumentasi. Sedangkan analisis data dalam penelitian ini menggunakan metoda fenomenologi dari Von Eckartsberg (Moustakas, 1994: 15-16). Langkahlangkah dalam metode ini adalah: perumusan masalah dan pertanyaan penelitian, data yang dihasilkan (teks pengalaman kehidupan), dan analisis data. Sedangkan pemeriksaan keabsahan data dilakukan dengan menggunakan triangulasi sumber.

\section{HASIL PENELITIAN DAN PEMBAHASAN}

\section{Keterwakilan Perempuan di Parlemen:} Menyoal Kuantitas dan Kualitas

Jumlah legislator perempuan di

DPRD Kota Bengkulu pada periode 20142019 adalah sembilan orang (26\%) dari total tiga puluh lima kursi yang tersedia. Walaupun belum mencapai angka30\%, jumlah ini telah mengalami peningkatan dibandingkan dengan periode sebelumnya yang berjumlah tujuh orang. Meski kalah dalam kuantitas, $30 \%$ perempuan anggota dewan berhasil melakukan lobi politik dan menduduki posisi ketua. Yang kemudian menjadi persoalan adalah, apakah tercapainya posisi tersebut dapat memberikan dampak signifikan bagi kemajuan perempuan dan keadilan gender di Indonesia? Menanggapi pertanyaan tentang diperhitungkanya suara perempuan di parlemen, Mardensi menyatakan bahwasanya perempuan belum cukup mampu bersuara sebagaimana hasil wawancara berikut:

"Sebenarnya, anggota di dewan ini kan 35 orang, perempuannya ada sembilan. Kadangkala memang, si perempuannya itu sendiri yang tidak mau memunculkan dirinya itu mampu. Itu saja. Kalau saya ya, kalau dalam rapat, apapun itu bentuk rapat, sekiranya saya harus berbicara ya saya berbicara. Jangan kita diam saja. Nah itu yang terjadi sekarang. Itu yang terjadi di dalam organisasi DPRD ini".

Senada dengan Mardensi, Erna Sari Dewi mengatakan:

"Di DPRD kota ini sudah lebih dari $30 \%$ anggota dewan yang perempuan, sudah sangat luar biasa keberadaanya. Artinya bahwa memang ke depan ini perempuanperempuan parlemen ini akan terus bertambah tetapi yang saya inginkan bukan kepada kuantitinya, bukan pada jumlah berapa banyaknya. Tetapi pada kualitas perempuan-perempuan parlemen. Perempuan-perempuan itu apa pun bidangnya dia harus cerdas".

Jawaban yang agak berbeda disampaikan oleh Baidari, SH yang menekankan pentingnya peran partai politik dalam mempengaruhi pemikiran dan aspirasi yang disampaikan oleh anggota dewan dalam setiap rapat. Dikatakannya:

"Kita biasanya sebelum mengeluarkan pendapat kompromi fraksi terlebih dahulu. Perbedaan pendapat biasanya dari partai. Kalau kita setuju dengan opsi dalam rapat, kita tidak banyak berbicara. Tapi kalau kita tidak setuju, kita akan berbicara".

Berkaitan dengan kontribusi pemimpin perempuan di parlemen untuk kemajuan dan kepentingan perempuan, disampaikan Mardensi:

"Ada beberapa kebijakan si, seperti ASI eksklusif, kita kan bantu. Kemudian Perda rokok. Perda rokok itu kan sangat penting buat kita. Perempuan hamil kan ga boleh menghisap asap rokok. Perempuan juga kalau lagi kerja kan risih kan nyium bau asap rokok. Itu.. Banyak si yang membela kaum perempuan" (wawancara 29 Agustus 2017). 
Sedangkan Erna Sari Dewi menyatakan:

"Memberi warna dengan kekhasan
perempuan yang dengan sensitive
memahami permasalahan di
masyarakat."

Menanggapi pertanyaan yang sama, Baidari menyatakan:

"Kalau dalam satu ruangan tidak ada perempuan rasanya tidak enak ya mbak ya. Karena ada perempuan lah kita bisa merangkul sebagai seorang ibu. Kalau laki-laki semua sama-sama keras semua.'

Berdasarkan hasil wawancara yang dilakukan kepada informan-informan di atas, nampak bahwa berhasil duduknya perempuan sebagai pemimpin di lembaga legislatif merupakan salah satu bentuk keadilan gender dan kemajuan terhadap perempuan. Namun demikian, walaupun secara kuantitas harapan para feminis melalui kebijakan kuota 30\% perempuan di parlemen sudah terpenuhi, secara kualitas, belum banyak kontribusi yang disumbangkan oleh para pemimpin tersebut bagi perempuan-perempuan yang mereka wakili.

\section{Perempuan Pemimpin dalam Maskulinitas Parlemen}

Kuatnya hegemoni patriarki yang berakar pada perspektif tentang kodrat, tugas, dan peran disebut Napsiah (dalam Sastriyani, 2009) sebagai kenyataan yang yang membuat perempuan semakin terpinggirkan dari sektor politik. Dilanjutkan Napsiah, meskipun beberapa perempuan telah muncul di parlemen, namun hal tersebut tidak didasarkan pada kemauan politik yang harus diperjuangkan. Walau begitu, beberapa perempuan tetap dapat menduduki posisi strategis. Lalu bagaimana dengan pemimpin-pemimpin parlemen di kota Bengkulu? Ketika ditanya tentang keberhasilan perempuan melawan hegemoni patriarki dan menduduki posisi pimpinan Mardensi mengatakan:

"Dengan cara pendekatan. Kita menampilkan sosok kita yang bisa merayu, yang bisa memberikan masukan kepada kawan-kawan dimana kawan-kawan merasa nyaman".

Sedangkan Baidari mengatakan:

"Dulu waktu kita pertama kali masuk di dunia politik, ketua komisi dua mau langsung kita rebut. Tetapi tidak dapat, selisih satu suara. Ketika periode kedua ini, mungkin karena kita sudah membaur selama 2,5 tahun. Dia jadi tahu kita ini siapa. Dan kita mengajukan untuk jadi ketua komisi dua sangat gampang. Kebetulan dari 12 orang itu 10 yang memilih kita. Kita gini mbak, kita sistem barteran, ada dengan PKB kita menjanjikan wakil ketua dan partai lainnya menjadi sekretaris. Dan teman-teman lainnya kita juga ada kerjasama yang baik”.

Jawaban senada disampaikan oleh Erna Sari Dewi yang mengatakan:

"Acceptabilitas masyarakat yang tinggi meyakinkan anggota akan kapabilitas yang saya miliki."

Menanggapi respon legislator lain ketika perempuan terpilih untuk memimpin laki-laki di "dunia laki-laki", dikatakan Mardensi:

"Responnya positif.. Mungkin karena keibuan tadi ya.. Keibuan, udah biasa tantangan di majelis ta'lim. Kalau di majelis ta'lim tu banyak perempuanperempuan yang kita hadapi ya, BKMT itu bermacam-macam, beragam manusianya. Kalau yang ini melaporkan yang ini, atau mengadukan yang ini, kita harus 
berada di tengah-tengah, tidak boleh mengadu domba. Itu saja".

Tanggapan yang sama disampaikan Baidari sebagai berikut:

"Alhamdulillah tidak ada masalah. Bukan karena kita membagi-bagi juga tidak. Modal kepercayaan saja dan komunikasi yang baik."

Hal lain yang menjadi isu berkenaan dengan kepemimpinan perempuan adalah diragukannya kemampuan mereka dalam memimpin dan stereotip-stereotip yang dilekatkan kepada pemimpin perempuan. Mendapatkan pertanyaan tentang isu ini, Erna Sari Dewi mengatakan:

"Meragukan atau tidak tergantung pribadi anggota dewan masingmasing. Sejauh memiliki kapasitas, kapabilitas maka acceptabilitas orang terhadap kepemimpinannya akan baik. Itu pasti berbanding positif",.

Sedangkan Mardensi menyatakan:

"Paling yang meragukan itu lawan politik kita yang mau jadi capil. Ada waktu itu. Adalah ya lawan politik kita kan yang menganggap o kecil melawan ibu Mardensi, kan ibu-ibu. Tapi karena kita sudah dengar itu, makanya kita harus antisipasi. Antisipasinya bahasa dia kita sebarkan kepada kawan-kawan. Itu sudah jadi satu hal negatif bagi dirinya. Jadi kita harus mengayomi tadi.."

Berbeda dengan Mardensi, menjadi perempuan dirasakan Baidari sebagai kekuatan tersendiri. Disebutkannya:

"Kita sebagai perempuan diutamakan. Seperti seorang ibu. Kita mengayomi dan mengajak bersama. Tidak ada komplain."

Berkenaan dengan stigma/stereotip yang dilekatkan kepada perempuan untuk bergabung di dunia politik, Mardensi mengatakan:

"Itu begini, kita dengan mitra kerja tidak boleh untuk menyalahkan. Tidak boleh untuk menggurui. Makanya kita harus isi mengisi. Kalau kita saling mengisi antara temen, itu tidak bakal terjadi" .

Sedangkan Baidari mengatakan:

"Kadang-kadang tidak enak hati, kalau dari segi perempuan sering merajuk. Kita di dunia politik harus mengenal watak seseorang."

Hal yang berbeda disampaikan oleh Erna Sari Dewi:

"Perempuan itu pasti lebih ingin
(memikirkan) menyelesaikan suatu permasalahan'; 'bagaimana bisa meringankan beban masyarakat'; itu sensitiftas yang dimiliki perempuan. Artinya perempuan disisi lain juga punya kelebihan punya perasaan yang halus untuk bisa kemudian mengakomodir berhubungan langsung dengan kebutuhan-kebutuhan masyarakat tersebut."

Berdasarkan hasil wawancara di atas, terlihat bahwa hegemoni laki-laki di dunia politik masih dirasakan. Dalam konteks penelitian ini, perempuan berada di dua sisi berlawanan. Di satu sisi, kemampuan perempuan masih diremehkan sehingga harus berusaha lebih keras untuk membuktikan kemampuan menjadi legislator dan pemimpin yang baik. Di sisi yang lain, perempuan terlalu "dimanja" dan dipandang perlu dibantu agar dapat menjalankan tugasnya dengan baik.

\section{Komunikasi Politik Perempuan- Perempuan Pemimpin di Parlemen}

Kuatnya dominasi maskulinitas dalam tatanan sosial memaksa perempuan untuk 
berjuang lebih keras supaya mampu menampilkan diri sebagai pemimpin. Dalam menjalankan tugas kepemimpinan sehari-hari yang berhubungan dengan komunikasi politik seperti dalam rapat komisi, berikut respon Mardensi ketika mendapat pertanyaan mengenai perbedaan keadaan rapat yang dipimpin oleh perempuan/laki-laki. Dikatakannya:

"Tergantung dengan pemimpinnya. Ada kalanya pemimpin itu arogan. Ada anggapan perempuan itu lebih cerewet dan lebih arogan. Pasti orang tidak suka. Ada juga pemimpin lakilaki yang kasar, namun dermawan misalnya. Kalau kita, kita ambil saja, karena kita seorang pemimpin, kita harus bisa menempatkan diri pada tempatnya. Bukannya kita harus tidak jaim, kita harus tetap terbuka tapi kepemimpinan kita harus tetap kita tunjukkan dengan cara yang santun, merangkul, mengarahkan".

Sedangkan Baidari mengatakan:

"Nggak ada si mbak, sama aja".

Jawaban yang diberikan Erna Sari Dewi adalah:

"Ada sentuhan unik sendiri ketika perempuan menjadi leadernya dan ketika laki-laki menjadi leadernya. Ada sentuhan-sentuhan perempuan yang kemudian yang tidak bisa lakilaki memberikan sentuhan itu. Sentuahn dalam artian positif ya. Bagaimana perempuan kemudian bisa lebih dekat dengan masyarakat. Ada sentuhan-sentuhan hati, bekerja dengan hati. Itu kelebihan perempuan itu adalah anugrah yang harus disyukuri."
Pertanyaan berikutnya adalah mengenai perbedaan "ketegasan" versi perempuan dan laki-laki. Disebutkan Mardensi:

"Tidak juga ada perbedaan sih.. Pokoknya sebagai pemimpin kita harus bisa menyesuaikan diri”.

Jawaban senada disampaikan oleh Baidari:

"Tidak juga. Kalau kita tegas-tegas benar, teman-teman pada lari. Cuma kita kasih pengertian tentang kegiatan yang harus kita lakukan. Mereka juga akan lebih enak, daripada kita tegastegas kita jutek-jutek mereka lari”.

\section{Sedangkan Erna Sari Dewi mengungkapkan:}

"Tidak ada, perempuan juga bisa tegas. Sekarang permasalahannya, apakah perempuan itu mampu mengeksplor dirinya, mengeluarkan sетиа kemampuan dirinya. Itu tergantung pribadi masing-masing. Mengelola sumber daya yang dia punya".

Berdasarkan hasil wawancara di atas terlihat bahwa para pemimpin perempuan di DPRD Kota Bengkulu berusaha untuk menyesuaikan diri dan melakukan komunikasi politik dengan gaya keibuan yang santun, merangkul, mengayomi, dan mengarahkan. Mereka mengaku tidak mau menerapkan komunikasi yang bersifat arogan, tegas, atau bersikap cerewet karena hal tersebut mereka pandang tidak tepat untuk diterapkan dalam kepemimpinan mereka.

\section{Idealitas Gaya Kepemimpinan: Feminin atau Maskulin}

Hubungan antara stereotip karakter dengan jenis kelamin tertentu berdampak pada cara pandang kepemimpinan dalam suatu organisasi atau lembaga. Organisasi sering dipandang sebagai sesuatu yang rasional, analitikal strategis, berorientasi 
pada keputusan, keras, dan agresif yang lebih mirip dengan karakter laki-laki (Parashakti, 2015). Hal ini pada akhirnya membawa implikasi bagi perempuan ketika menyandang posisi sebagai pemimpin. Ketika ditanya tentang perlunya menerapkan sikap "maskulin" agar "dipandang" dalam memimpin Mardensi mengatakan:

"Sebenarnya menjadi pemimpin itu harus menyesuaikan dengan keadaan. Kalau terlalu tegas, kasar ya tidak baik juga"

Jawaban senada disampaikan oleh Baidari dan Erna Sari Dewi. Dikatakan Baidari:

"Dalam memimpin tidak harus jiwa kelaki-lakian. Jiwa keibuan pun yang penting saling menghargai. Antar komisi juga saling musyawarah, saling komunikasi, itu saja intinya."

Sedangkan Erna Sari Dewi mengatakan:

"Justru di dalam dunia politik ini sangat memerlukan sentuhan perempuan. Kenapa saya bilang begitu, perempuan itu lebih bekerja dengan hati. Ketika misalnya dia turun ke lapangan, melihat masyarakat kemudian menyalurkan aspirasinya untuk disampaikan terus kemudian menyampaikan keluhankeluhan, perempuan itu lebih gampang tersentuh. Jadi saya tidak memandang bahwa, dunia politik ini dunia maskulin, tidak".

Kemudian ketika ditanya mengenai ada atau tidaknya keterbatasan/tindakan yang tidak dapat Anda lakukan sebagai pemimpin karena perempuan, Mardensi mengatakan:

"Kalau saya tidak.. Memang kadang ada si, seperti kalau rapat Banggar pas bulan puasa itu sahur baru bisa pulang. Tapi kalau saya tidak sih, karena keluarga mendukung. Paling kalau mau pergi kunjungan ke Jakarta, kulkasnya harus dipenuhi, persiapan anak-anak apa, susunya, lauknya harus disiapin dulu. Semua itu tidak terlepas dari bantuan saudara-saudara kita yang di rumah, asisten rumah tangga terutama" (wawancara 29 Agustus 2017).

Menanggapi pertanyaan yang sama Baidari mengatakan:

"Tidak ada selama ini suami juga sangat mengerti dan men-support, misalkan rapat paripurna hingga malam, asalkan tujuan benar."

Hal senada disampaikan oleh Erna Sari Dewi:

"Jangan perempuan takut diremehkan, jika kita punya kemampuan lebih baik. Ini bukan soal feminine atau maskulin, bukan soal antara laki-laki dan perempuan. Ini soal kemampuan pribadi seseorang. Ketika makanya saya bilang maka perempuan itu harus cerdas. Perempuan itu harus banyak membaca. Harus terus setiap hari menambah wawasannya, supaya tidak disepelekan. Ketika bidangnya adalah politik, maka geluti politik bidang itu dengan baik. Maka jadilah dia politikus yang baik."

Hal berikutnya yang menjadi isu dalam kepemimpinan perempuan adalah hubungan antara ketua dengan anggota komisi. Menanggapi pertanyaan tentang hierarki yang terjadi di dalam institusi/komisi yang pernah dipimpin, Mardensi mengatakan:

"Di komisi yang saya pimpin kita terbuka. Kita nggak berjenjang”

Sedangkan Baidari mengatakan:

"Sebenarnya tidak ada yang menonjolkan. Tapi misalnya di undangan, yang membuka ketua fraksi kalau tidak datang bisa kita wakilkan 
dengan wakil ketua. Kalau dari segi apapun ketua kan lebih, anggota biasa aja."

Kemudian ketika ditanyakan tentang orientasi dalam hubungan organisasi, Mardensi mengatakan:

"Saya sifatnya merangkul ya.. jadi tugas harus tetap dilaksanakan tapi hubungan baik juga tetap dijaga"

Di sisi lain, Baidari mengatakan:

\section{"Alhamdulillah dekat."}

Berbicara tentang idealitas gaya kepemimpinan, ketika ditanya mengenai adakah yang akan diubah dari gaya kepemimpinan yang diterapkan, Mardensi mengatakan:

"Paling dalam hal menambah ilmu. Karena dulu waktu masuk saya kan masih S1, saya merasa masih kurang. Ini saya baru saja menyelesaikan $S 2$, sidang tesis sudah. Tinggal nunggu wisuda saja. Itu saja si yang ingin diperbaiki"

Sedangkan Baidari menyampaikan:

"Tidak ada yang ingin saya ubah. Saya ke masyarakat tidak akan mengubah. Karena yang memilih saya kan masyarakat, misalnya ada pengajian saya tetap sediakan kuenya, semua kita cover mulai dari ustadnya. Kita membentuk itu sebagai wadah. Saya kemarin juga kampanye bukan untuk jadi menjabat tapi jadi anggota dewan yang mampu merangkul orang miskin."

Sedangkan jawaban yang diberikan Erna Sari Dewi adalah:

"Nah ini jadi anggota dewan ini kok gak punya apa-apa. Tapi bagaimana rakyat bisa mempercayai kembali nanti kepada yang bersangkutan ketika dia tidak bisa mewakili suara rakyatnya. Jadi itu akan terlihat karena masa periode itu lima tahun, maka akan terlihat di tahun-tahun berikutnya. Apakah masyarakat kemudian bisa mempercayakan kembali kepada wakil rakyatnya yang mampu bekerja dan yang tidak mampu bekerja akan terlihat"

Dari hasil wawancara di atas terlihat bahwa para informan menganggap kepemimpinan perempuan yang menerapkan "sifat-sifat" feminin yang bersifat merangkul dan keibuan lebih ideal dibandingkan dengan gaya kepemimpinan yang terlalu tegas atau kasar. Berkenaan dengan hierarki dan orientasi dalam organisasi, mereka mengatakan bahwa walaupun hierarki bersifat terbuka dan berorientasi pada hubungan, mereka juga bersikap tegas agar tugas-tugas yang diemban oleh anggota parlemen yang mereka pimpin tetap dilaksanakan.

\section{PENUTUP}

Berdasarkan hasil penelitian yang dilakukan di lapangan, dapat disimpulkan bahwa:

1. Dari segi kuantitas, kuota $30 \%$ yang diharapkan belum juga terpenuhi. Sedangkan dari segi kualitas, perempuan-perempuan yang telah berhasil duduk di kursi dewan belum memberikan banyak kontribusi, baik dalam produk-produk kebijakan yang berperspektif gender maupun dukungan nyata bagi kemajuan kaum perempuan di dunia politik.

2. Komunikasi politik dan gaya kepemimpinan dilakukan para perempuan pemimpin dengan gaya keibuan seperti melakukan pendekatanpendekatan yang bersifat merangkul, mengajak, dan mengarahkan anggota parlemen yang mereka pimpin untuk menjalankan tugas. Namun begitu, 
ketika dipandang perlu, mereka tetap bersikap tegas, namun tidak arogan.

\section{DAFTAR PUSTAKA}

Kriyantono, Rakhmat. 2009. Teknik Riset Komunikasi. Jakarta, Prenada Media Group

Ma'ruf, Ade. 2013. Megawati Soekarnoputri: Riwayat Pribadi dan Politik Putri Bung Karno. Yogyakarta, Ar-Ruzz Media.

Moustakas. 1994. Phenomonological Research Method. California, Sage Publication.

Napsiah. 2009. Nilai-nilai Profetik dan Affirmative Action di Partai Politik". Dalam Siti Hariti Sastriyani (Eds.), Gender and Politics. Diterbitkan atas kerjasama Pusat Studi Wanita Universitas Gadjah Mada dengan Penerbit Tiara Wacana. Hlm. 171-176.

Parashakti, Ryani Dhyan. 2015. Perbedaan Gaya Kepemimpinan dalam Perspektif Maskulin dan Feminin. Jurnal Ilmiah Manajemen dan Bisnis Vol I, No. I, Maret 2015. Hlm. 92-101.

Richmond-Abbot, Marrie. 1992. Masculine and Feminine:Gender Roles Over the Life Cycle. New York: McGraw-Hill.

Suryani, Indah. 2010. Partisipasi Perempuan dalam Komunikasi Politik (Studi tentang artisipasi Perempuan dalam Komunikasi Politik di Pos Wanita Keadilan (Pos-WK) Dewan Pengurus Daerah (DPD) Partai Keadilan Sejahtera (PKS) Sukoharjo Tahun 2009). SKRIPSI. Fakultas Ilmu Sosial dan Ilmu Politik Universitas Sebelas Maret Surakarta

Syah, Sirikit. 2014. Membincangkan Pers, Kepala Negara, dan Etika Media. Jakarta: PT. Elex Media Komputindo.

Thoha, Miftah. 2010. Perilaku Organisasi: Konsep Dasar dan Aplikasinya. Jakarta: RajaGrafindo Persada.
Tong, Rosemarie Putnam. 1998. Feminist Thought (Diterjemahkan oleh AquariniPriyatnaPrabasmoro). Yogyakarta: Jalasutra.

Zamroni, Muhammad. 2013. Perempuan Dalam Kajian Komunikasi Politik dan Gender.Jurnal Dakwah, Vol. XIV, No. 1 Tahun 2013

Sumber Online

2016. Margaret Thatcher Biography. http://www.biography.com/people/ margaret-thatcher-9504796 diakses tanggal 21 Mei 2016 pukul 14.23 WIB. 